\title{
Effect of Surface Treatment and Particle Loading on the Mechanical Properties of CFB Fly Ash Reinforced Thermoset Composite
}

\author{
Joy Erika P. Reyes
}

\begin{abstract}
Circulating fluidized bed (CFB) boilers, a relatively new and more environment-friendly technology, produce fly ash with limited use on the construction industry. This study focused on the use of CFB fly ash as a filler material in thermoset composites. CFB fly ash was treated with coconut oil using the procedure used by Yao et al. (2013). The fly ash was applied to orthophthalic unsaturated polyester resin at different particle loading. The untreated and treated fly ash were characterized by scanning electron microscopy (SEM), Fourier transform infrared spectroscopy (FTIR), and X-ray fluorescence (XRF). Tensile and flexural properties of composites with varying fly ash loading were measured using universal testing machine (UTM). The tensile and flexural modulus increased while the tensile and flexural decreased with increasing particle loading. Improvement in the mechanical properties of the composites with treated fly ash relative to the ones with the untreated was observed. This is caused by enhanced particle-matrix adhesion and improved particle dispersion. Moisture absorption caused a decline in the flexural properties of the composites. Water acted as a plasticizer so the matrix weakened upon immersion.
\end{abstract}

Index Terms-CFB fly ash, mechanical properties, moisture absorption, particle filled composite, polyester composite.

\section{INTRODUCTION}

The Philippines energy consumption is continuously increasing. In terms of energy sales, there is an increase of 8.6 percent from $50,686 \mathrm{GWh}$ in 2009 to $55,266 \mathrm{GWh}$ in 2010 [1]. Coal is and will continue to be the main source of energy in the Philippines. Mainly because coal is the largest reserve and is often the cheapest among the fuel options [2].

Combustion of coal using more environmentally-friendly technologies, such as circulating fluidized bed (CFB) combustion, is getting more attraction. Also, the Department of Energy is promoting the use of clean coal technology so it is expected that the number of power plants using CFB boilers will continue to increase. Aside from its contribution to the environment, $\mathrm{CFB}$ boilers are capable of burning low quality coal, lignite, and alternative fuels like biomass [3]. However, this technology produces fly ash that has limited applications in the cement and concrete industry as well as land reclamation restoration [4]. Cement industry is one of the end-users of the fly ash produced from

Manuscript received May 15, 2014; revised July 1, 2014. This work was supported by the Philippine Department of Science and TechnologyEngineering and Research Development for Technology.

Joy Erika P. Reyes is with the Department of Chemical Engineering, University of the Philippines - Diliman, Quezon City, Philippines (e-mail: joyerikareyes@gmail.com). conventional technology. CFB fly ash does not meet the standard composition of coal fly ash for use in concrete according to ASTM C618-D12a [5]. Fly ash is considered an environmental pollutant [6] so there is really a need to focus on finding an industry where CFB fly ash can be put into significant use.

There are published studies that focus on using CFB fly ash in different applications. One of which is the use of hydrated fly ash as pavement construction materials. The disadvantage presented in the study is it is not recommended for applications that involve water contact so additional considerations are needed for the said material to be used in road construction [7]. $\mathrm{CaO}$ and $\mathrm{CaSO}_{4}$ found in fluidized bed fly ash form hydration products, such as potlandtite and ettringite, that cause volume expansion. These hydration products are significantly larger than the reactants. So this phenomenon may cause expansion cracks due to delayed reactions with water [8]. Another study focused on the extraction of zeolitic materials from CFB fly ash and its use in heavy metal removal from wastewater [9]. This does not solve the problem of disposal since after adsorption, the fly ash is needed to be disposed. Autoclaved brick was produced by Zhang et al. (2012) from CFB fly ash and slag. Autoclaving was done to prevent volume expansion when in contact with water [10]. But the disadvantage of autoclaving is it is process requiring high energy. Another possible use of fly ash, which is the focus of this study, is as a filler material in polymer composites. Filler materials are generally inert materials which are used in composite materials to reduce material costs and to improve mechanical properties (Singla et al., 2010). This study will investigate the effects of reinforcement with CFB fly ash to the mechanical properties of the polymer composite. The matrix to be used is unsaturated orthophthalic polyester because it is readily available and can be cured at low temperature. Composites using unsaturated polyester resin matrix have been used in naval construction, offshore applications, water lines and building construction [11].

The use of fly ash as filler material in polymer composite is still not widespread. The main reason is the weak interfacial bonding between the untreated fly ash and polymer matrix. One of the solutions to address this problem is surface modification of the fly ash to increase the surface area and improve interfacial bonding by chemical treatment [12]. A recent study on CFB fly ash - polymer composite focused on the use of stearic acid as the fly ash surface treatment [13].

Fatty acids are considered as non-coupling agent in particle-filled composites. In this study, the CFB fly ash 
will be coated with fatty acids from coconut oil and the effects on the mechanical properties will be investigated.

The main goal of this study is to develop a composite reinforced with CFB fly ash. It also aims to investigate the mechanical properties of the composite. This aims to investigate the effect of particle loading, surface treatment, and moisture absorption on the mechanical properties of the composite.

\section{MATERIALS AND METHODS}

\section{A. Materials}

The CFB fly ash was sourced from a paper manufacturing plant situated in Calumpit, Bulacan, Philippines. A single polymer resin type, unsaturated orthophthalic polyester resin R 10-103, from Polymer Products (Phil) Inc., was the composite matrix of all the samples to be prepared. The polymer hardener (methyl ethyl ketone peroxide) and the mold release (Durawax ${ }^{\circledR}$ ) were also procured from the same supplier. The coconut oil used was Minola ${ }^{\circledR}$ Premium Lauric Oil which is available commercially.

\section{B. Chemical Treatment of Fly Ash}

The treatment procedure is based on the method of Yao et al. (2013) [13]. $200 \mathrm{~mL}$ of water was added to $100 \mathrm{~g}$ of fly ash in a $600-\mathrm{mL}$ beaker. The $\mathrm{pH}$ of the slurry was adjusted to 8 using concentrated sulphuric acid. $3 \mathrm{~g}$ of coconut oil was dissolved in $62 \mathrm{~mL}$ of ethanol at $60^{\circ} \mathrm{C}$ in a $60-\mathrm{mL}$ beaker. Then the fly ash slurry was slowly added to the oilethanol mixture under vigorous mixing at $1500 \mathrm{rpm}$. The mixing continued for $30 \mathrm{mins}$ at $30^{\circ} \mathrm{C}$. The fly ash was filtered from the solution and it was washed with hot ethanol $\left(60^{\circ} \mathrm{C}\right)$ until there was no crystallization in the filtrate. The fly ash was then dried in an oven at $110^{\circ} \mathrm{C}$ for 12 hours.

\section{Preparation of Composites}

Prior to preparation of the resin mixture, the molds, aluminium flat bars, metal sheets, and plastic films (commercially available as OHP acetate) were coated with Durawax ${ }^{\circledR}$. Stainless steel molds were used for tensile test samples while flat bars forming a rectangular frame for flexural test samples. Then the materials were assembled in the press as follows (from the bottom): metal sheet, plastic films and molds/flat bars.

The resin and hardener was mixed at a weight ratio of 100:1.5 in a PET container. CFB fly ash was added at varying compositions (10 wt $\%, 20 \mathrm{wt} \%, 30 \mathrm{wt} \%$ and 40 $\mathrm{wt} \%$ ) and the slurry was mixed for 5 mins using a hand mixer operated at the maximum speed. A vacuum desiccator was used to remove the entrapped air from the mixture. The fly ash resin mixture was poured into previously prepared molds. Then plastic films were carefully placed on top of the molds making sure that no air was trapped inside. Another metal sheet was placed on top of the molds before the press was closed. The temperature of the press was maintained at $55^{\circ} \mathrm{C}$ for 6 hours.

The samples were removed from molds after curing. The rectangular slabs were cut into $127 \mathrm{~mm} \times 12.7 \mathrm{~mm}$ strips. The edges were refined using metal file and sand papers.
Prior to testing, the width and thickness of all samples were measured using a digital calliper.

\section{Mechanical Test}

Mechanical tests were carried out using a Shimadzu Ultimate Testing Machine. Tensile test is based on ASTM D638 [14] while the three-point bending test is from ASTM D790 [15].

\section{E. Flexural Test with Moisture Absorption}

All samples were dried at $50^{\circ} \mathrm{C}$ in the heat press for 1 hour. Before soaking, the weights of the samples were measured using a Radwag Analytical balance. Nine specimens for each loading were soaked in distilled water. The setup was kept at room temperature during the course of the test. Every 24 hours, three specimens for each loading were weighed and subjected to flexural test.

\section{RESULTS AND DISCUSSION}

\section{A. Hydrophobicity of CFB Fly Ash}

Table I shows the mineralogical composition as analysed using X-ray fluorescence (XRF) of the untreated fly ash. Oxides, which are polar compounds, comprise the untreated fly ash so it is expected that the fly ash is hydrophilic.

TABLE I: XRF ANALYSIS OF CFB FLY ASH

\begin{tabular}{cc}
\multicolumn{2}{c}{ TABLE I: XRF ANALYSIS OF CFB FLY ASH } \\
\hline \hline Components & Composition (\%) \\
\hline $\mathrm{SiO}_{2}$ & 35.65 \\
$\mathrm{Al}_{2} \mathrm{O}_{3}$ & 20.12 \\
$\mathrm{Fe}_{2} \mathrm{O}_{3}$ & 10.00 \\
$\mathrm{CaO}$ & 21.43 \\
$\mathrm{MgO}$ & 2.99 \\
$\mathrm{SO}_{3}$ & 4.34 \\
$\mathrm{~K}_{2} \mathrm{O}$ & 1.13 \\
$\mathrm{Na}_{2} \mathrm{O}$ & 1.08 \\
$\mathrm{LOI}$ & 3.47 \\
\hline \hline
\end{tabular}

The hydrophobicity of the particle plays an important role in the interaction with the polymer matrix. Since polymer is hydrophobic, it is favourable for the particle to be hydrophobic for a better adhesion. In Fig. 1, the water penetrated to the surface of the untreated fly ash while the surface of treated fly ash repelled the water. This shows that treatment causes the fly ash to be hydrophobic.

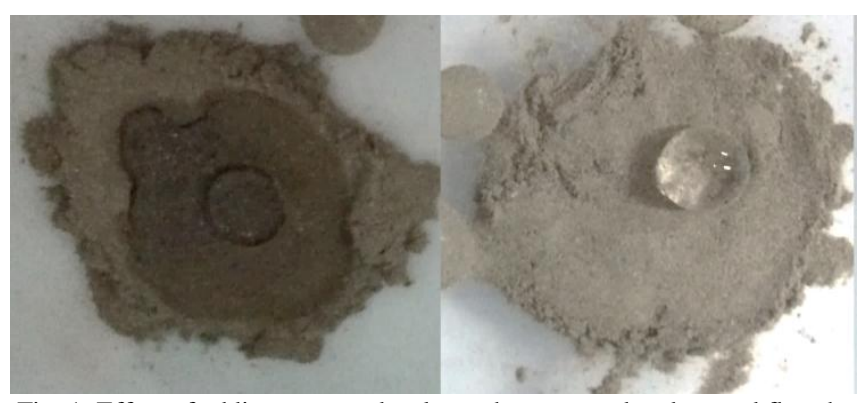

Fig. 1. Effect of adding a water droplet to the untreated and treated fly ash. 


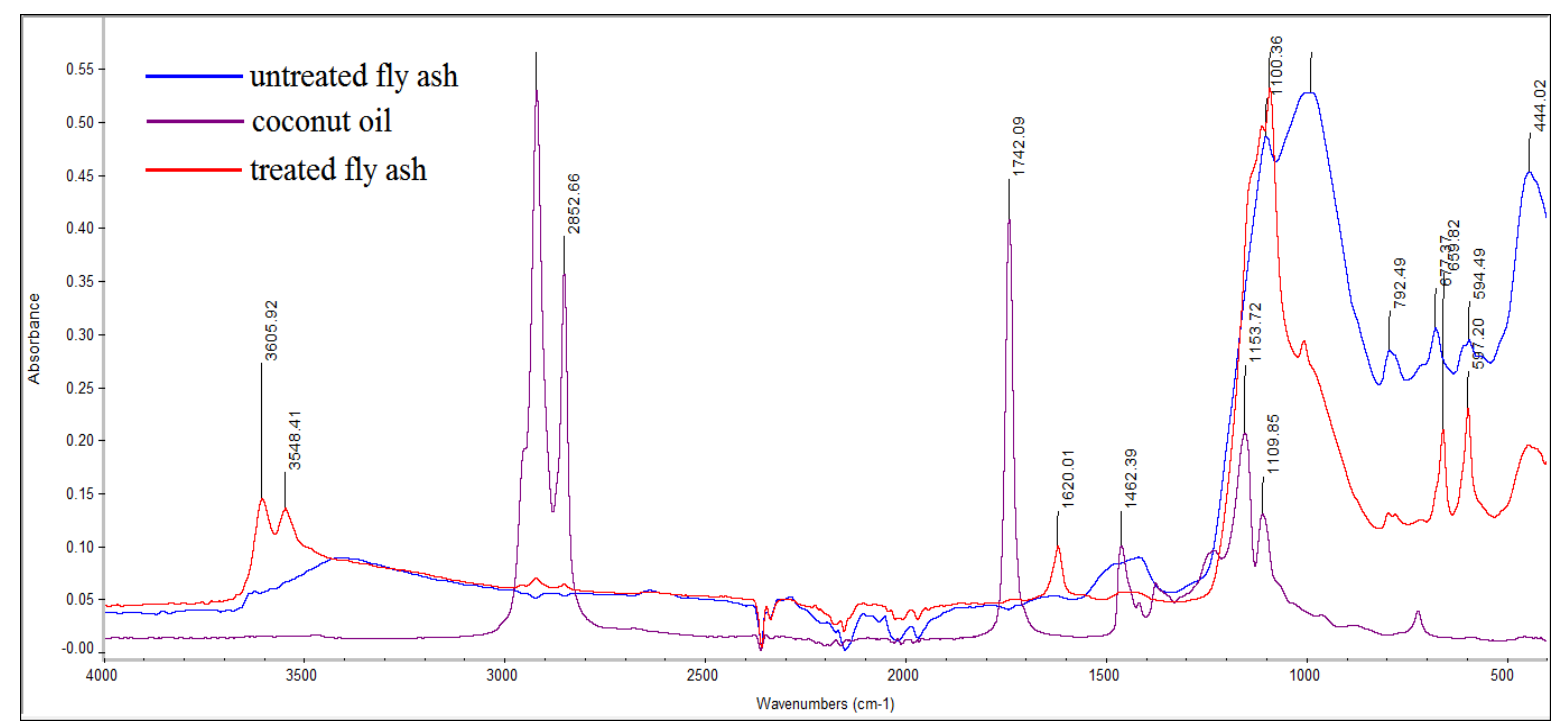

Fig. 2. FTIR analysis of untreated and treated fly ash and coconut oil.

\section{B. Fourier Transform Infrared Spectroscopy (FTIR) of CFB Fly Ash}

Fig. 2 shows the FTIR spectra of untreated fly ash, coconut oil, and treated fly ash. The peaks at $3605 \mathrm{~cm}^{-1}$ and $3548 \mathrm{~cm}^{-1}$ in the treated fly ash is due to $\mathrm{OH}$ stretch and is indicative of presence of alcohol. This may be due to the residual ethanol used in washing the fly ash. The peaks at $2850-2990 \mathrm{~cm}^{-1}$ indicates the presence of $-\mathrm{CH}_{3}$ and $-\mathrm{CH}_{2}$ in aliphatic compounds ( $\mathrm{CH}$ stretching) in the coconut oil. The aliphatic compounds are from the saturated fatty acid present in the oil. A slight increase in absorbance from the untreated fly ash to treated fly ash is found in the same region. This means that the saturated fatty acids are coated on the fly ash. The peak at $1742 \mathrm{~cm}^{-1}$ directs the presence of fatty acid $(\mathrm{C}=\mathrm{O}$ stretch $)$ in the coconut oil. This peak is absent in the fly ash spectra since the carboxylic acid functional group reacted with the fly ash during treatment. The broad band at around $1000 \mathrm{~cm}^{-1}$ is caused by ( $\mathrm{Si}-\mathrm{O}-\mathrm{Si}$ ) asymmetric stretching vibration. This coincides with the presence of $\mathrm{SiO}_{2}$ from the XRF analysis of fly ash. The peaks and bands at 1100 and $660 \mathrm{~cm}^{-1}$ are indications of (Si$\mathrm{O})$ and (Al-O) vibrations respectively [16]. The absorbance at these three wavenumbers decrease in the treated fly ash spectrum. Surface coating may have caused the compounds found in the untreated fly ash to decrease in absorbance.

A probable reaction of the coating mechanism of fatty acid on the surface of the fly ash is shown in Fig. 3.

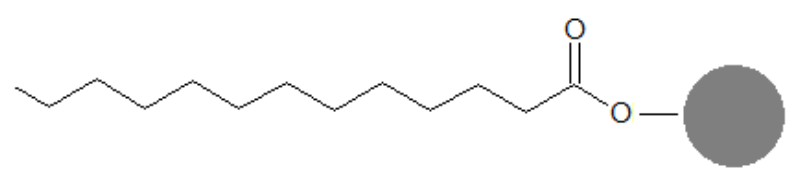

Fig. 3. Probable reaction between fly ash and fatty acid.

\section{Scanning Electron Microscopy (SEM) of CFB Fly Ash}

The particle size is decreased upon treatment as seen in Fig. 4. The shape changed from cloud-like to glass-like structures. The change in particle size and structure may be caused by the addition of sulphuric acid during the $\mathrm{pH}$ adjustment of the slurry. Addition of acid caused an increase in temperature of the slurry which is the result of the exothermic reaction between the acid and the ash [17]. Treatment caused a smoother surface of the fly ash. Fatty acid coating on the surface may have caused this change.

\section{Mechanical Properties}

The results of mechanical tests are compared with existing models. Fu et al. (2008) summarized the theories for predicting modulus and strength of a particle-filled composite. The models presented here are Einstein's and Guth's equations for modulus, and linear and Nielsen's equation for strength. The experimental values are fitted in the models described below.

Einstein's equation for predicting the modulus of particulate composites

$$
\frac{E_{c}}{E_{m}}=1+2.5 V_{p}
$$

where $E_{c}$ and $E_{m}$ are the modulus of the composite and matrix, and $V_{p}$ is the particle volume fraction. The above equation is useful for low particle loading but is not suitable for large loading due to interaction between particles. Guth added a particle interaction term to the Einstein's equation:

$$
\frac{E_{c}}{E_{m}}=1+2.5 V_{p}+14.1 V_{p}^{2}
$$

Assuming that the load is not transferred from the matrix to the filler, the strength of the composite is given by:

$$
\sigma_{c}=\sigma_{m}\left(1-V_{p}\right)
$$

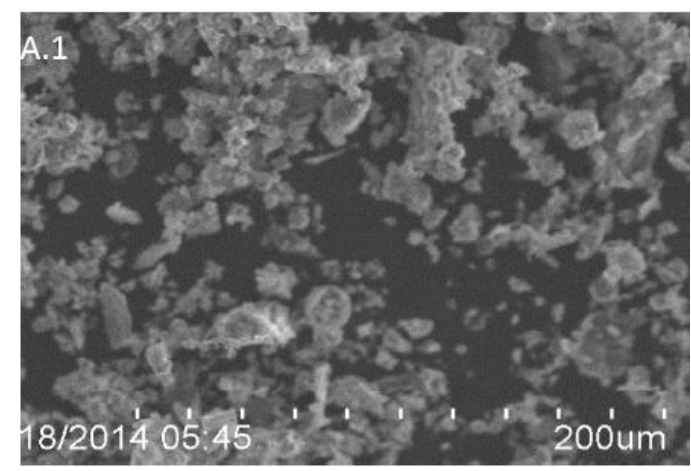



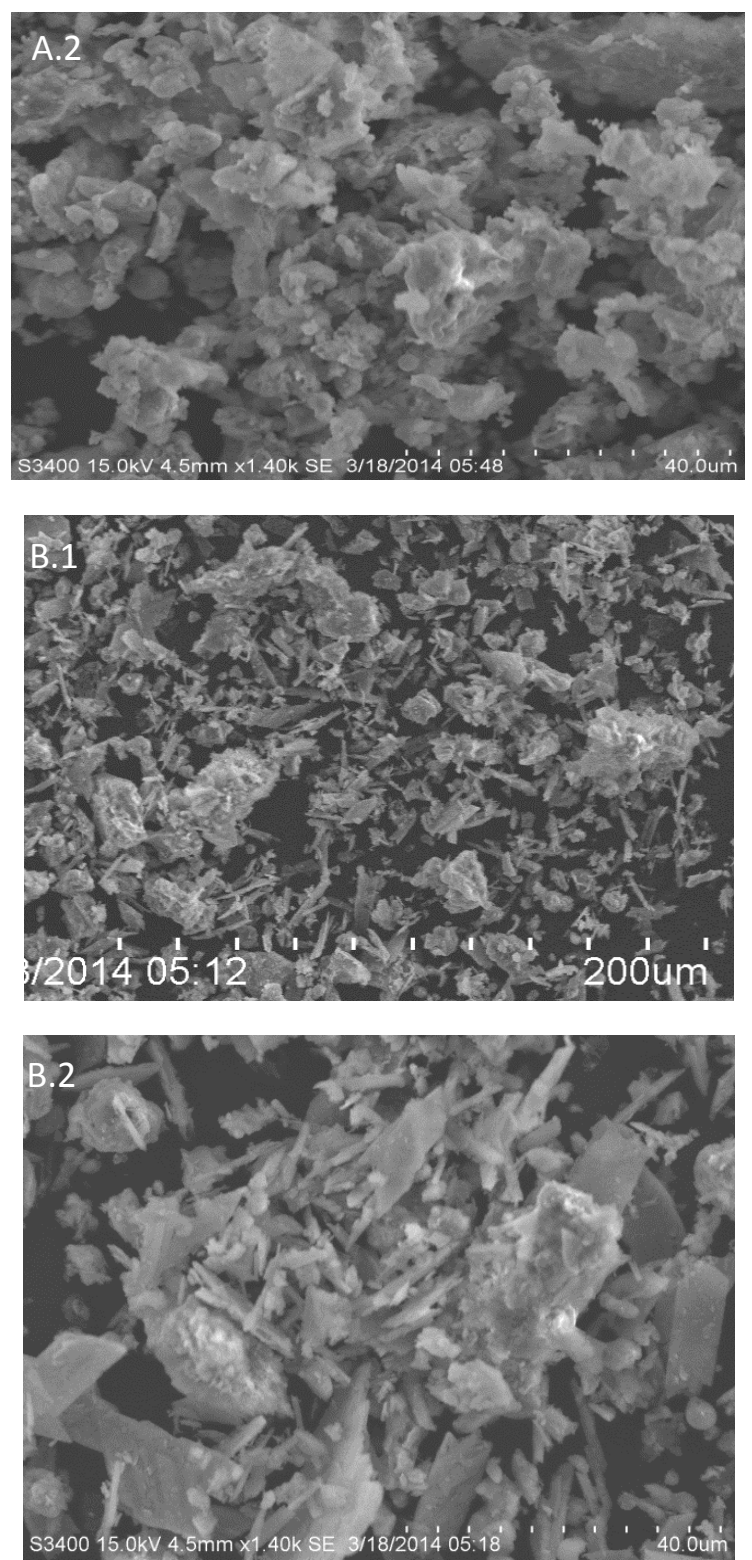

Fig. 4. Scanning Electron Microscopy (SEM) images of (A) untreated fly ash and (B) treated fly ash.

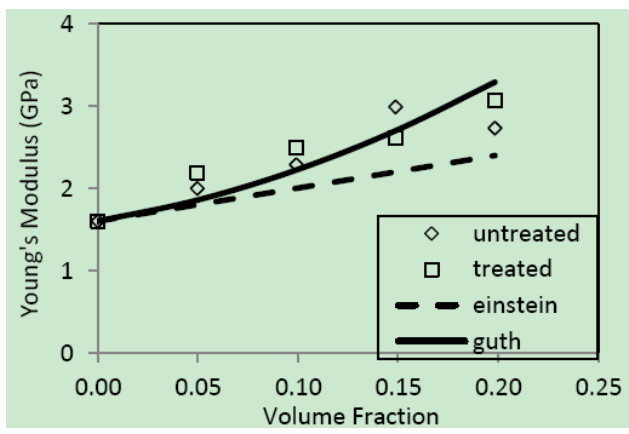

Fig. 5. Young's modulus of composites with different particle loading of untreated and treated fly ash.

where $\sigma_{c}$ and $\sigma_{m}$ are the composite strength and matrix strength, respectively. A non-linear relationship is predicted by the Nielsen's equation as given below.

$$
\sigma_{c}=\sigma_{m}\left(1-V_{p}^{\frac{2}{3}}\right) Q
$$

where $Q$ accounts for the weakness due to stress concentration at the particle/polymer interface. Here, $Q$ is assumed to be 1 or there is no stress concentration [18].
The Young's modulus of the composites with untreated and treated fly ash is presented in Fig. 5. Increase in particle loading causes an increase in Young's modulus. The experimental data shows similar trend with both models used but Guth's equation gives a better fit. This is expected since Guth's is an improvement of the Einstein's equation.

As seen in Fig. 6, the flexural modulus of the composites with increasing particle loading for both untreated and treated fly ash. This trend follows both Einstein's and Guth's equations however, Guth's equation gives a better fit.

The modulus is expected to increase upon addition of particle fillers. In general, particle fillers are more rigid compared to the polymer matrix so addition causes increase in the rigidity of the composite [18].

The effect of particle loading on the tensile strength of samples containing untreated and treated fly ash is shown in Fig. 7. The tensile strength decreases with increasing particle loading for both set of samples. The data points for the untreated samples do not fit with any of the model used. One reason for this is maybe agglomeration of particles caused voids in the samples. For the treated samples, the linear model shows a better correlation. This says that the treatment does not improve the transfer of stress from the matrix to the particle since the linear model assumes that the matrix alone carry the load.

Fig. 8 shows the effect of particle loading on the flexural strength of composites containing untreated and treated fly ash. Increase in particle loading decreases the flexural strength of the composites. The trend is consistent with both models used. Nielsen's equation gives a better fit for both treated and untreated samples.

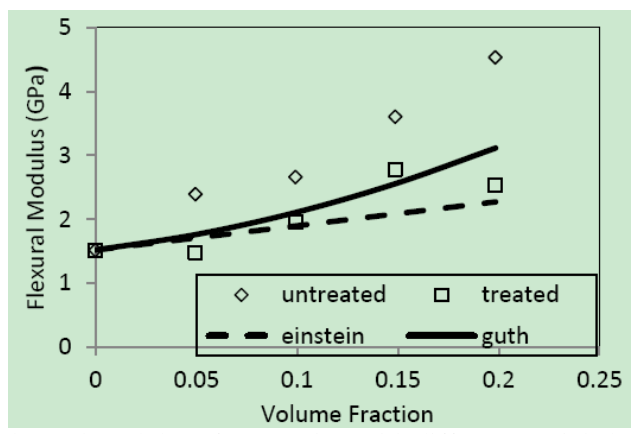

Fig. 6. Flexural modulus of composites with different particle loading of untreated and treated fly ash.

The decrease in strength of the composites is caused by poor dispersion of fillers, presence of agglomerates or existence of defects such as voids. Poor particle-matrix interaction causes decline in the strength of the composite [19]. Agglomeration of particles can cause voids between the particles and between the agglomerates and matrix so weak points arise from increasing the particle loading [18].

The treated fly ash was used in the composite and the mechanical properties are then observed. As seen in Fig. 5, the samples with treated fly ash give higher modulus values as compared to the ones with the untreated. This small increase may have been caused by a slight improvement in the particle-matrix adhesion. The modulus values of the samples with treated fly ash, as presented in Fig. 6 are lower compared to those with untreated fly ash. Treatment may have caused a plasticizing effect so the composited with treated fly ash are more flexible. 


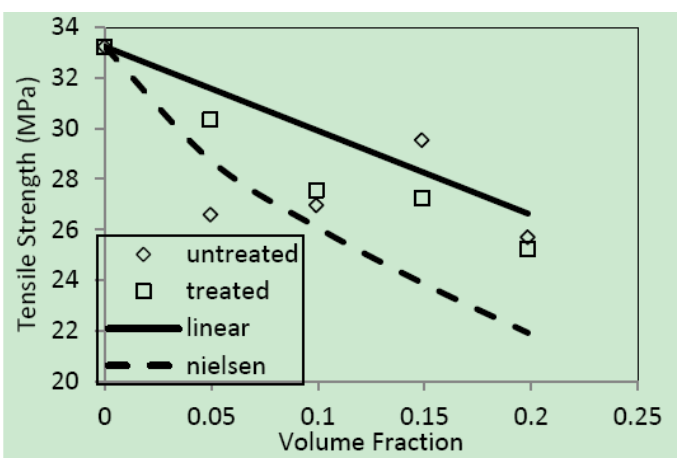

Fig. 7. Tensile strength of composites with different particle loading of untreated and treated fly ash.

From Fig. 7, the tensile strength values show that treatment causes an improvement in the relationship between strength and particle loading. As previously mentioned, agglomerations may have caused the unexpected behavior of the strength of the samples with untreated fly ash. Treatment improves the dispersion of the particles in the matrix so voids due to agglomeration are minimized.

Improvement in the strength from untreated to treated is evident in higher particle loading as shown in Fig. 8. This may be caused by agglomeration of particles due to poor particle-matrix interaction. Weak points may arise from voids between particles in the agglomerates. Treatment may not have favoured the formation of agglomerates indicating that the dispersion of particles in the matrix is improved.

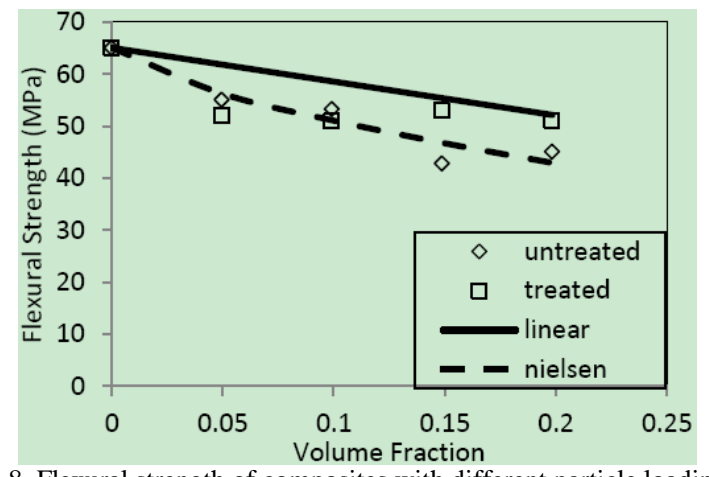

Fig. 8. Flexural strength of composites with different particle loading of untreated and treated fly ash.

Surface treatment does not produce a drastic improvement on the modulus and strength of the composite. The treatment process is not optimized so the fatty acids may be weakly adsorbed on the surface of the fly ash or not every fly ash particle was coated with fatty acid. In the addition of treated fly ash to the polyester resin, the coating may have been affected by the high-speed mixing of the fly ash-resin slurry.

\section{E. Effect of Moisture Absorption on Flexural Properties}

The effect on water absorption on the flexural modulus and strength for different particle loading is shown in Fig. 9 and Fig. 10. Both the modulus and strength decrease with increasing amount of absorbed water. The neat resin absorbed less water compared to the composites. This is because of the hydrophilic nature of the fly ash so the composites tend to absorb more water. The effect of particle loading on the amount of absorbed water is not observable during short time of soaking (72 hours).

The decline in flexural properties is caused by matrix plasticization [20]. Plasticization involves interruption of bonds within the polymer matrix. Water molecule penetrates into the interspace of macromolecular chains by diffusion and causes matrix swelling. The glass transition temperature of the matrix decreases after swelling so the modulus decreases. There is also a chemical reaction between the plasticizer and the macromolecules (e.g. hydrolysis) so the main chain ruptures, thus the strength is reduced. In the case of unsaturated polyester, hydrolysis of ester causes micro cracks within the material [21]. Some authors observed that matrix plasticization reduces mechanical properties during the first stage of immersion while delamination occurs during long term immersion [20]. Matrix swelling is not observed during the time of immersion.

A different trend is observed for $30 \%$ particle loading. In this case, maybe the absorption of moisture of both the matrix and the fly ash caused a different trend. In the other samples, the matrix plasticization may have dominated.

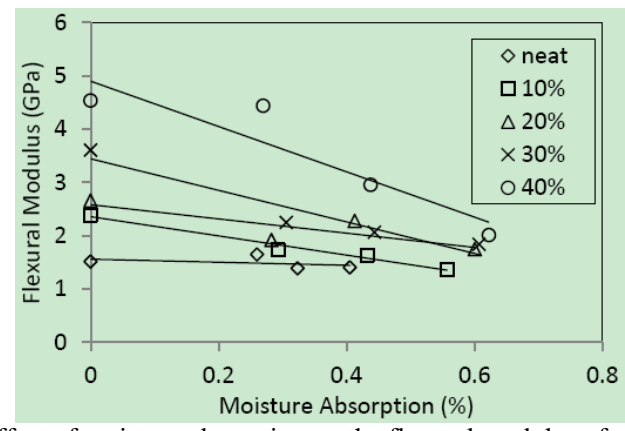

Fig. 9. Effect of moisture absorption on the flexural modulus of composites with different particle loading.

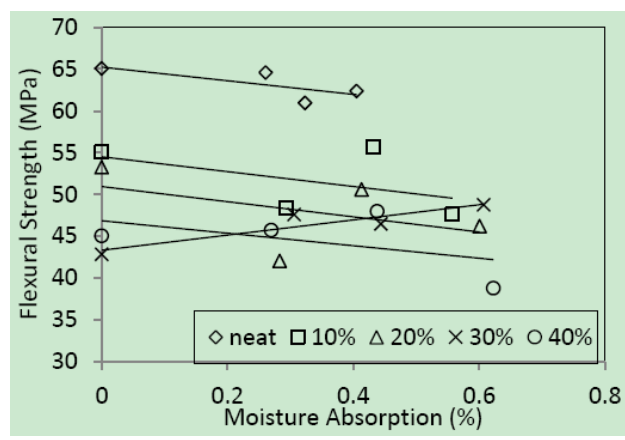

Fig. 10. Effect of moisture absorption on the flexural strength of composites with different particle loading.

\section{CONCLUSION}

A thermoset composite reinforced with CFB fly ash was successfully developed and its mechanical properties were studied.

Increasing the particle loading increases the tensile and flexural modulus and decreases the tensile and flexural strength. The increase in modulus is due to the addition of more rigid particle fillers. The decrease in strength is caused by the weak particle-matrix adhesion. Poor adhesion does not allow the transfer of stress from the matrix to the fillers.

Similar trend is observed with the samples containing treated fly ash. The tensile and flexural moduli increase while the tensile and flexural strength decrease as the particle loading is increased. Improvement in the tensile 
modulus relative to the untreated samples may have been caused by the improved interfacial adhesion. The flexural modulus declined compared to the untreated samples. Treatment may have a plasticizing effect on the composite. Both the tensile and flexural strength improve because of the prevention of the formation of agglomerates. Treatment may have improved the dispersion of the particles in the matrix.

Absorption of moisture decreases the flexural strength and modulus of the composites for most particle loading. Matrix plasticization caused the decline in flexural performance since absorption of moisture weakens the matrix.

\section{ACKNOWLEDGMENT}

The author would like to thank the Department of Chemical Engineering, University of the PhilippinesDiliman especially to Dr. Terence Tumolva. This study was funded by the Department of Science and Technology Engineering Research and Development for

\section{REFERENCES}

[1] Power Planning and Development Division, "Philippine Power Sector Situationer," Department of Energy, 2010

[2] Department of Energy. [Online]. Available: http://www.doe.gov.ph/fossil-fuels/coal

[3] N. Koukouzas, C. R. Ward, D. Papanikolaou, Z. Li, and C. Ketikidis, "Quantitative evaluation of minerals in fly ashes of biomass, coal and biomass-coal mixture derived from circulating fluidised bed combustion technology," Journal of Hazardous Materials, pp. 200207, 2009.

[4] N. Koukouzas, J. Hamalainen, D. Papanikolaou, A. Tourunen, and T. Jantti, "Mineralogical and elemental composition of fly ash from pilot scale fluidised bed combustion of lignite, bituminous coal, wood chips and their blends," Fuel, vol. 86, pp. 2186-2193, 2007.

[5] American Society for Testing and Materials, "Standard Specification for Coal Fly Ash and Raw or Calcined Natural Pozzolan for Use in Concrete," 2012.
[6] M. Ahmaruzzaman, "A review on the utilization of fly ash," Progress in Energy and Combustion Science, pp. 327-363, 2010.

[7] N. M. Jackson, S. Schultz, P. Sander, and L. Schopp, "Beneficial use of CFB ash in pavement construction applications," Fuel, pp. 12101215,2009

[8] B.-M. Steenari, S. Schelander, and O. Lindqvist, "Chemical and leaching characteristics of ash from combustion of coal,peat and wood in a 12 MW CFB - a comparative study," Fuel, vol. 78, pp. 249-258, 1999.

[9] N. Koukouzas, C. Vasilatos, G. Itskos, I. Mitsis, and A. Moutsatsou, "Removal of heavy metals from wastewater using CFB-coal fly ash zeolitic materials," Journal of Hazardous Materials, vol. 173, pp. 581-588, 2010.

[10] Z. Zhang, J. Qian, Y. Chao, and C. Hu, "Use of circulating fluidized bed combustion fly ash and slag in autoclaved brick," Construction and Building Materials, pp. 109-116, 2012.

[11] L. B. Manfredi, E. S. Rodriguez, M. Wladyka-Pryzbylak, and A. Vazquez, "Thermal degradation and fire resistance of unsaturated polyester, modified acrylic resins and their composites with natural fibres," Polymer Degradation and Stability, pp. 255-261, 2006.

[12] Y.-F. Yang, G.-S. Gai, Z.-F. Cai, and Q.-R. Chen, "Surface modification of purified fly ash and application in polymer," Journal of Hazardous Materials, vol. B113, pp. 276-282, 2006.

[13] N. Yao, P. Zhang, L. Song, M. Kang, Z. Lu and R. Zheng, "Stearic acid coating on circulating fluidized bed combustion fly ashes and its effect on the mechanical performance of polymer composites," Applied Surface Science, vol. 279, pp. 109-115, 2013.

[14] American Society for Testing and Materials, "Standard Test Methods for Tensile Properties of Plastics," 2010

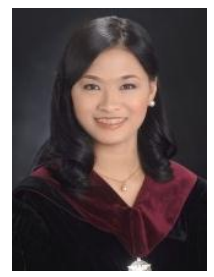

Joy Erika P. Reyes is a member of the Philippine Institute of Chemical Engineers and University of the Philippines Chemical Engineering Society, Inc. She was born in Rizal, Philippines on September 29, 1990. She received her master and bachelor of science degrees in chemical engineering from the University of the Philippines-Diliman, Quezon City, Philippines in 2012 and 2014 respectively. She is a licensed chemical engineer and passed the November 2012 chemical engineering licensure exam held in Manila, Philippines. 